\title{
Indian manufacture of new generic antiretrovirals: implications for global access to anti-HIV drugs
}

"The Indian decision suggests that in the future, developing-world patent offices may take a tougher stance than industrialized countries as to which drugs merit patents."

\section{India's ruling on patent protection}

India recently rejected patent applications on two antiretrovirals (ARVs), darunavir and tenofovir, which ensures the continued generic manufacturing of these drugs at substantially reduced costs compared with proprietary formulations [1]. The ruling by India's Patent Office (IPO) to reject the exclusive licensing of the nucleoside reverse-transcriptase inhibitor tenofovir (Gilead Sciences, CA, USA) and protease inhibitor (PI) darunavir (Tibotec Pharmaceuticals, NJ, USA) also allows other countries to import generic versions produced in India. Cipla, the Mumbai-based generic drug manufacturer, had filed cases against both companies. Even before the anticipated outcome, Gilead had already offered 13 Indian drug manufactures the licensing rights to manufacture tenofovir, but with the caveat that the Indian manufacturers purchase the active drug ingredient from Gilead and that the product be sold only to the poorest 95 countries (which does not include middle-income countries, such as China and Brazil). The patent rejection potentially opens up the market for generic drug manufactures to further drive down the cost of these two ARVs, and may have wider implications for the future development and distribution of ARVs.

\section{India's role in expanding access to generic ARVs}

India is not the first country to reject a patent on tenofovir, but rather, this decision follows a similar one made by Brazil and the US Patent Office. India's decision highlights section 3(d) of India's patent law, prohibiting 'evergreening', in which multinational pharmaceutical companies can make small, trivial changes to existing medicines in order to extend the period of a patent monopoly on a drug. This practice by pharmaceuticals has the impact of preventing the entry of generic competitors into the market and keeping drug prices high [101]. India is currently bound by the World Trade Organization (WTO) Trade-Related Aspects of Intellectual Property Rights (TRIPS) agreement, which safeguards intellectual property rights by providing a 20-year warranty securing the inventor exclusive rights $[2,3]$. In line with the WTO obligations, India has granted Pfizer and Tibotec the rights for the entry-blocking drug maraviroc, and the new non-nucleoside reverse transcriptase inhibitor etravirine, respectively [3]. The concern is that new Indian patent laws that comply with the WTO obligations will impede the development of generic versions of HIV drugs, pitting patients against patents.

Since the 1970s, the Indian Patents Act has allowed the production of generic versions of drugs where a slight modification in manufacturing could qualify a drug for a new patent [4]. This provision has allowed Indian drug manufacturers to coformulate ARVs at prices as low as $4 \%$ of the brand-name versions. Although the current generation of coformulated ARVs will continue to be available at reduced costs, the question is, what will be the future of new generic ARVs that are likely to be needed to maintain continued access to an expanded formulary of affordable HIV therapy?

\section{Need for greater access to generic ARVs in resource-limited settings}

Today, HAART continues to be made ever more sustainable, effective and simpler, but the need for treatment on a global scale has grown with the continued rise in the number of HIVinfected individuals [5]. The number of individuals receiving HAART must be put within the larger context of the estimated 33 million who are currently living with HIV [102]. Although close to 4 million individuals are estimated to
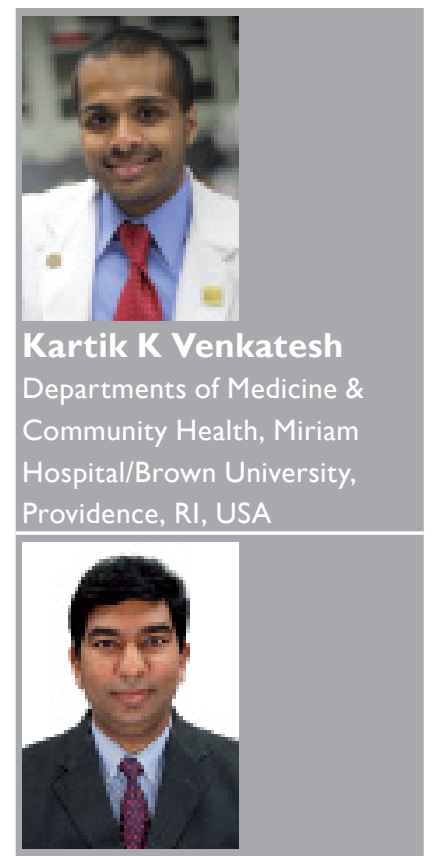

Nagalingeswaran

Kumarasamy

YR Gaitonde Centre for AIDS

Research \& Education, Voluntary Health Services, Chennai, India

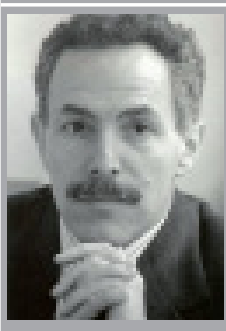

Kenneth H Mayer ${ }^{\dagger}$ ${ }^{\dagger}$ Author for correspondence: Departments of Medicine \& Community Health, Miriam Hospital/Brown University, Providence, RI, USA Tel.: +I 401793471 ; Fax: +I 401793 4709; kenneth_mayer@brown.edu

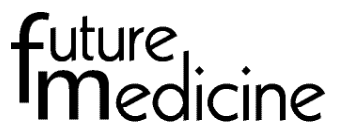


be currently receiving antiretroviral therapy (ART), this only represents approximately $31 \%$ of the population in need of treatment $[3,102]$. Nevertheless, based on the experience of Brazil, even after producing generic $A R V$ s, the costs of providing scaled-up HAART rises over time as individuals develop progressive disease, standards of care change and new drugs become available [6]. A current debate exists as to whether HIV treatment should be utilized at higher $\mathrm{CD}^{+}{ }^{+} \mathrm{T}$-cell counts to minimize the chronic effects of untreated HIV disease [7]. Consequent changes in treatment guidelines will result in increasing the need of ARVs around the world.

\section{"Developing nations will need to balance the needs of patients who need access to these drugs at reduced prices while still rewarding innovation through patent protection."}

Owing to the continued decline of $\mathrm{CD}_{4}{ }^{+}$ T-cell counts in untreated patients, the vast majority of currently HIV-infected individuals will be in need of treatment within the next decade. This means that by 2015 most of the 38 million currently HIV-infected patients will have become eligible for treatment based on current WHO treatment guidelines. A question that nations with a high HIV burden will have to consider is that with a growing number of patients failing first-line HAART and requiring second-line therapy, how should the need of second-line HAART be balanced with the unmet need of patients who are still requiring first-line HAART? When scaling-up ART, nations must develop means of negotiating a balance between sustainability of treatment programs and equitable access in order to provide structured, indefinite, chronic HIV care [8].

\section{Evidence for an expanded ARV drug formulary}

A large formulary of readily available ARVs is crucial to transform HIV infection from a fatal disease into a chronic illness [4]. In addition, despite the proven safety, tolerability and efficacy of generic ARVs $[9,10]$, these drugs must be monitored for proven bioavailability and bioequivalence in addition to satisfactory manufacturing, distribution and administration [11]. The availability of fixed-dose generic therapeutics, such as lamivudine, stavudine and nevirapine, as a single combination for less than US $\$ 1$ a day, had set the stage for the further expansion of HAART across the developing world. However, any optimism generated for this regimen as a global, universal, first-line treatment has now been tempered by the realities of stavudine- and nevirapineassociated toxicities. A more promising option may be a fixed-dose combination of tenofovir, emtricitabine and efavirenz, which is a simple, safe and well-tolerated regimen [12]. Tenofovir is increasingly becoming a key HIV/AIDS drug, recommend by the WHO for improved first-line treatment regimens owing to price negotiations undertaken through public and private donors.

Despite the increasing availability of fixed-dose, generic, first-line regimens, second-line regimens continue to be up to 10-times the cost of firstline agents due to a lack of adequate generic formulations. Darunavir is a new and expensive agent, which is needed in patients experiencing treatment failure. As a larger number of patients initiate ART across the developing world, failure of first-line treatment is inevitable among patients [13]. The Indian National AIDS Control Organization (NACO) is currently providing free access to second-line ARVs to 5000 patients with first-line drug resistance. It is estimated that in the near future, the rate of 5-year switching could range between 5 and $40 \%$, based on the individual country [14]. However, only a quarter of patients in resource-limited settings and on second-line therapy are on drug combinations recommended by current WHO guidelines, in contrast to patients on first-line HAART, where almost all patients are on recommended combinations [15]. Therefore, there is a need to rapidly expand the formulary of second-line PI regimens that are in concordance with the WHO guidelines as part of national treatment programs [17]. Given the improved treatment outcomes of patients initiating second-line PI containing HAART, further efforts are needed to improve the timely diagnosis of treatment failure on first-line therapy and expand access to second-line regimens.

\section{Implications of the Indian ruling on future HIV drug development}

Scale-up of ART may soon be replaced with the new mantra of sustainability, which requires a wide armamentarium of ARVs to meet the needs of patients who have been living with HIV for decades. It is conceivable that in the near future companies could legally challenge the current decisions by the IPO through filing a second patent application. Multinational pharmaceuticals could face considerable financial loses and a reduced market share in developing-world markets with the generic manufacturing of 
ARVs. The Indian decision suggests that in the future, developing-world patent offices may take a tougher stance than industrialized countries as to which drugs merit patents. A concern is whether rulings, such as that by India, could hamper and disincentivize the development of new ARVs, such as integrase inhibitors, by multinational pharmaceuticals wary of losing their patent rights.

\section{"This provision has allowed Indian drug manufacturers to coformulate ARVs at prices as low as $4 \%$ of the brand-name versions."}

Developing nations will need to balance the needs of patients who require access to these drugs at reduced prices while still rewarding innovation through patent protection. Three strategies that have already been developed to expand access to generic ARVs include procurement arrangements to increase purchase volumes, third-party consultation and price negotiation with generic ARV suppliers, and differential pricing (also referred to as price discrimination or tiered pricing) [16]. Newer strategies to further reduce ARV costs include the further removal of institutional barriers for generic entry, improved forecasting of future ARV demands in order to avoid emergency drug shipments, technology transfer to generic manufacturers and publicly accessible procurement databases to guide evidence-based drug policies. The Clinton Foundation HIV/AIDS Initiative (CHAI) has been involved in decreasing the prices of ARVs by working in collaboration with both generic and branded pharmaceutical manufacturers. Individual countries have also utilized the differential pricing mechanisms established by branded pharmaceuticals, though it has been suggested that these prices remain substantially higher compared with those offered through CHAI [3,17]. The US FDA under US President's Emergency Plan for AIDS Relief (PEPFAR) allows for the purchase of generic ARVs to be provided outside the US.

There needs to be mechanisms to allow the protection of intellectual property rights in order to continue to incentivize major pharmaceutical companies to produce the next generation of ARVs while still providing for the production of quality-controlled generic versions to meet the large-scale treatment needs of patients in resource-limited settings. The greatest cost of providing universal HIV treatment for a country remains the direct drug costs paid to the manufacturer. Hence, further constructive negotiations between international organizations, governments and pharmaceuticals are crucial to achieve the goal of expanded access to ART. Funding the future of sustainable ART will require a shared multifaceted approach, involving a combination of government revenue, private sector programs, international development assistance and contributions from other private foundations.

\section{Financial \& competing interests disclosure}

The authors have no relevant affiliations or financial involvement with any organization or entity with a financial interest in or financial conflict with the subject matter or materials discussed in the manuscript. This includes employment, consultancies, honoraria, stock ownership or options, expert testimony, grants or patents received or pending, or royalties.

No writing assistance was utilized in the production of this manuscript.

\section{Bibliography}

1 Majumdar B: India patent rejections welcomed by HIV/AIDS groups. Reuters, 9 September (2009).

2 Butler D: India says no to HIV drug patents: patent office rejects applications from two US drug companies. Nat. News, 3 September (2009).

3 Dionisio D, Fabbri C, Messeri D: HIV drug policies and south markets: settling controversies. Therapy 5(5), 707-717 (2008).

4 Havlir D, Hammer SM: Patents versus patients? Antiretroviral therapy in India. N. Engl. J. Med. 353(8), 749-751 (2005).
5 Quinn T: HIV epidemiology and the effects of antiviral therapy on long-term consequences. AIDS 22(Suppl. 3), S7-S12 (2008).

6 Nunn A, Fonseca EM, Bastos FI, Gruskin S, Salomon JA: Evolution of antiretroviral drug costs in brazil in the context of free and universal access to aids treatment. PLoS Med. 4(11), e305 (2007).

7 Kitahata M, Gange SJ, Abraham AG et al.; NA-ACCORD Investigators: Effect of early versus deferred antiretroviral therapy for HIV on survival. N. Engl. J. Med. 360 (18), 1815-1826 (2009).

8 Harries A, Schouten EJ, Libamba E: Scaling up antiretroviral treatment in resource-poor settings. Lancet 367(9525), 1870-1872 (2006).
9 Kumarasamy N, Solomon S, Chaguturu SK et al.: The safety, tolerability, and effectiveness of generic antiretroviral drug regimens for HIV-infected patients in south India. AIDS 17, 2265-2271 (2003).

10 Laurent C, Kouanfack C, Koulla-Shiro S et al.: Effectiveness and safety of a generic fixed-dose combination of nevirapine, stavudine, and lamivudine in HIV-1-infected adults in Cameroon: open-label multicentre trial. Lancet 264, 29-34 (2004).

11 Bartlett J, Muro EP: Generic and branded drugs for the treatment of people living with HIV/AIDS. J. Int. Assoc. Physicians AIDS Care 6(1), 15-23 (2007). 


\section{EDITORIAL | Venkatesh, Kumarasamy \& Mayer}

12 Hirsch M: Initiating therapy: when to start, what to use. J. Infect. Dis. 197(Suppl. 3), S252-S260 (2008).

13 Orrell C, Harling G, Lawn SD et al: : Conservation of first-line antiretroviral treatment regimen where therapeutic options are limited. Antivir. Ther. 12(1), 83-88 (2007).

14 Renaud-Théry F, Nguimfack BD, Vitoria M et al.: Use of antiretroviral therapy in resource-limited countries in 2006: distribution and uptake of first- and second-line regimens. AIDS 21(Suppl. 4), S89--S95 (2007).

15 Beck E, Vitoria M, Mandalia S, Crowley S, Gilks CF, Souteyrand Y: National adult antiretroviral therapy guidelines in resource-limited countries: concordance with 2003 WHO guidelines? AIDS 20(11), 1497-1502 (2006).

16 Waning B, Kaplan W, King AC, Leufkens HG, Fox MP: Global strategies to reduce the price of antiretroviral medicines: evidence from transactional databases. Bull. World Health Organ. 87(7), 520-528 (2009).

17 Vasan A, Hoos D, Mukherjee JS, Farmer PE, Rosenfield AG, Perriëns JH: The pricing and procurement of antiretroviral drugs: an observational study of data from the Global Fund. Bull. World Health Organ. 84(5), 393-398 (2006).

\section{- Websites}

101 MSF response to India's rejection of patents on key HIV/AIDS drugs (2009). http://www.msfaccess.org/main/accesspatents/msf-response-to-india-s-rejection-ofpatents-on-key-hivaids-drugs/

102 United Nations. 2008 update on the global AIDS epidemic. www.unaids.org/en/KnowledgeCentre/ HIVData/GlobalReport/2008/2008_ Global_report.asp 